\title{
Review of Practical Dermatopathology by Ronald P. Rapini
}

\author{
Review by Mark A. Hurt, M.D.
}

Citation: Hurt MA. Review of Practical Dermatopathology by R Rapini. Dermatol Pract Conc. 2013;3(4):12. http://dx.doi.org/10.5826/ dpc.0304a12.

Copyright: @2013 Hurt. This is an open-access article distributed under the terms of the Creative Commons Attribution License, which permits unrestricted use, distribution, and reproduction in any medium, provided the original author and source are credited.

Corresponding author: Mark A. Hurt, M.D., 2326 Millpark Dr, Maryland Heights, MO 63043, USA. Tel. 314.99.4470. Email: markhurt@ aol.com.

\section{“A Transition”}

Dear Readers of the Book Reviews,

It is now some 10 years since I became the book review editor of Dermatopathology: Practical \& Conceptual. When that journal closed and became Dermatology Practical \& Conceptual, I stayed on as the editor of the book reviews.

It has been quite a run; I have edited some 40 reviews across both journals, and I hope it has kept you, the reader and the central purpose of this journal, engaged intellectually. I have certainly been challenged, and I have appreciated the opportunity to engage with all of you.

Now it is time for me to retire from being the editor of the book reviews. I appreciate all of the help provided me by the staff of Derm101.com and especially the guidance of the late Bernie Ackerman, his successor, Almut Böer, and her successor, Harald Kittler.

Now as Iris Zalaudek takes on of the role of editor-inchief of Dermatology Practical \& Conceptual, I wish her everything good for the continued high academic standards that have been established from the roots of the journal, which go back to 1995 . I know it will be a challenge for her.

All the best to her and all of you, from

Mark A. Hurt, M.D.

\section{Review by Mark A. Hurt}

In this second edition of Practical Dermatopathology, Dr. Rapini's mission is the same as in his prior version: "a practical approach to skin biopsies is presented to supplement existing books of dermatopathology.” This second edition is

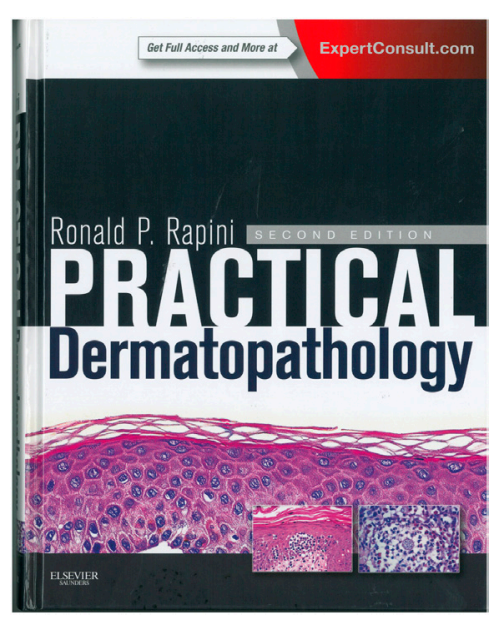

Rapini RP. Practical Dermatopathology. Second Edition. Edinburgh: Elsevier-Saunders. 2012; 450 pp with index and web access. ISBN 978-0-32306658-7. $\$ 150$.

much more extensive than the prior edition (which contained a CD-ROM) in that it provides also a code that one can use to gain access to the "Expert Consult" website, which contains all of the information in the book but provides also enhanced searching, some hypertext, and additional photographs (those in the book plus additional photographs only on the website).

In the introduction, the publisher highlights the website features specifically, as follows:

"Website Features

- Consult the book from any computer at home, in your office, or at any practice location.

- Instantly locate the answers to your clinical questions via a simple search query.

- Quickly find out more about any bibliographical citation by linking to its MEDLINE abstract.

- Images: Browse a Library of all book images. Easily select, organize, and download your images into a presentation. 
- Online-Only Images: Browse a Library of the additional online-only images. Easily select, organize, and download your images into a presentation.

- Review Questions: Test yourself, in either Study or Assessment mode, on these review questions."

In 2006, I reviewed the first edition of this book with these opening words: "Dr. Rapini's book is intriguing; it is a relatively concise 395 pages with few references to books or articles from the literature (153 total), but he does not hesitate to reference articles from this Journal, much to his credit. The book is organized as clues (Chapter 1) and as chapters (the remaining chapters) on specific categories of clinical findings or specific diseases, concluding with a chapter on special stains. The conditions are presented, mostly, as brief statements, often in numbered lists, about the specific clue or condition in question, which is without doubt a culmination of Dr. Rapini's many years of experience in practice, teaching, and writing about dermatopathology."

The second edition is somewhat larger than the first edition, it containing 55 additional pages. The basic structure of the book is similar to the 1 st edition, the chapter titles are identical, and, like the previous edition (as well as a good film or a good novel), one must read the preface and the first chapter to understand what Dr. Rapini is attempting to achieve.

In that chapter, Dr. Rapini lays the groundwork for the remainder of the book. It serves as the point of orientation for the reader who is looking to solve a diagnostic dilemma, as it provides differential diagnostic lists. For instance, if one identifies interstitial dermatitis under the microscope, he needs to turn only to chapter 1 , page 20 , that headlines that condition. There, it states the following:

“1.65 Interstitial dermatitis

This is defined as the unimpressive presence of inflammatory cells scattered in the spaces between collagen bundles in the dermis, as opposed to the more common perivascular dermatitis (1.109). It is not as dense as nodular and diffuse dermatitis (1.91) or lichenoid dermatitis (1.72). Of course, many of these other patterns may have a few interstitial inflammatory cells, but the list here primarily includes those where interstitial inflammation is the major finding.

Cellulitis (12.3)

Erythema marginatum (3.1 and 12.2)

Granuloma annulare (7.1)

Interstitial drug reaction (3.5)

Interstitial mycosis fungoides (24.1)

Sweet's syndrome (3.7, usually more diffuse)

Urticaria (3.1)

Well's syndrome (3.8, usually more diffuse)
Intertriginous eruptions (see Axilla 1.10 or Groin $1.55) ”$

The numbers to the right of the listed conditions refer to subsequent chapters to which the reader can refer to "drill down" to specific findings. The website version of the book recapitulates this almost exactly, but one downside on the website is that it does not provide hyperlinks to each condition listed above, which would have been a great enhancement. As it is, it is similar to the book but even easier to navigate.

The beauty of Dr. Rapini's method of orientation is that it provides an "in the moment" experience for anyone who is sitting a microscope and attempting to solve a diagnostic problem.

Do you see "pale epidermis"? If so, go to chapter 1, and there is an item by that name. Here is what it says:

“1.99 Pale epidermis

(see also Vacuolization of epidermis 1.144, Clear cell

neoplasms 1.22, Pagetoid cells 1.37)

Acrodermatitis enteropathica (17.1)

Hartnup's disease (2.1)

Necrolytic migratory erythema (3.2)

Pellagra (8.19)

Psoriasis (2.8)

Radiodermatitis (9.2)

Syphilis (2.13)"

Of course, if you don't like the idea of using an empirical findings list like those in chapter 1 , there is a 20 -page index, mostly in small print. The website also has the index hyperlinked to the sections in the book where the item(s) are found.

Similar to the prior version, the subsequent chapters are organized by topic and contain highlighted "P" areas that provide bullet points of key histopathological findings. The photographs are generally of high quality and are labeled with lines that show and list the specific findings, which is a great help to someone who is just beginning in the field. Additionally, the photographs can be downloaded from the website for use in lectures, etc.

In sum and in short, don't walk, RUN out to get this second edition of "Rapini." It is a terrific, useful, and enjoyable book to use every day at the microscope. I believe that residents and fellows in dermatopathology will find it useful, especially when combined with the website, which one can use at any computer or on an iPad. This $\sim \$ 150$ investment is well worth it.

Dr. Hurt is a dermatopathologist who practices in Maryland Heights, MO, USA, and he is the book review editor of Dermatology Practical \& Conceptual. Contact him at markhurt@aol.com 